\title{
Using Interactive Collaborative Media to Improve Skills of Mathematics Teachers to Educate Students with Special Needs during Covid-19 Pandemic
}

\author{
Marwa Nabil El-ahwal \\ Lecturer at Faculty of Education, Tanta University, EGYPT \\ marwa_nabeel@edu.tanta.edu.eg
}

\begin{abstract}
Using interactive collaborative media has demonstrated a significant improvement in the performance of the students participating in the experimental group concerning skills of mathematics teachers to educate students with special needs during covid-19 pandemic. Therefore, the would-be teachers have to be more creative and depend on innovative curricula for an effective learning; the thing which necessitates improving mathematics teachers skills. Experimental group included 30 participants whereas controlling group included 30 participants as well. After checking the similarity of the two groups and accepting variables, participants were chosen randomly. The practical method and quasi-experimental design were also used in the study. Results demonstrated differences with statistical significance of the skills of the experimental group: encouraging interaction and collaboration with colleagues and families, encouraging default interaction, designing mathematics lessons according to the comprehensive design for fairness and accessibility, educating mathematical concepts and skills, using technological teaching strategies and evaluating students.
\end{abstract}

Keywords: Interactive - collaborative - skills of mathematics teachers - students with special needs - covid-19 pandemic

\section{Introduction}

At the end of the year 2019, covid-19 swept Wuhan, the Chinese city, for the first time, and then moved to the whole world. Consequently, schools suspended their activities since March 15, 2020. Causing several economic, health and social problems, most educational institutions adapted to this severe experience by depending on online teaching and distance learning as a way for consuming learning.

However, that rapid transformation from traditional learning to default one suddenly (Laplante, 2020) forced many teachers to learn new techniques and teaching skills; the thing, which led to stress among teachers and students. Teachers faced several challenges during covid19 including providing equal opportunities for students, providing default teaching and serving special education for students with special needs (Smith, 2020).

Despite that rapid change in education systems, which guaranteed continuity of learning and stopping students' dropout, there were some doubts about effectiveness of distance learning (Sahu, 2020). As default learning is considered a great challenge for teachers, it is more difficult for those students who need social and emotional care. In addition, covid-19 decreased greatly support for students with special needs from special education teachers (Petretto et al, 2020). Yet, the main purpose of teaching students with special needs is to blending them with their community through providing equal and effective educational services at all schools of special education.

Educational institutions have to provide programs illustrating the importance of social, collaborative and emotional learning by parents (Smith et al, 2016; Turky, Shahin \& Soliman, 2020). Furthermore, those institutions must make a good use of the pandemic by training 
teachers to continue teaching by providing technical equipment and collaborative platforms plus educational activities (Smith, 2020). Consequently, teachers can satisfy requirements of students with special needs and help them achieve success in learning. Ministry of higher education and scientific research has been keen on coping with the latest Innovations through launching the first digital platform for distance learning for consuming study at universities depending on Microsoft Teams and letting office 365 available for all students to benefit from all Microsoft applications. For facilitating transforming from traditional methods to virtual ones during covid-19, teachers depended greatly on Microsoft services and applications through making default classes for the sake of protecting students' health. The study of (Durak \& Cankaya, 2020) investigated students ' opinions of using digital learning during covid-19. Results showed students satisfaction about using distance learning.

Covid-19 has affected negativity all students in general and students with special needs in particular. Unfortunately, both teachers and disabled students lack in the ability of applying technological skills on learning; $42 \%$ of teachers found it difficult to direct enough support for disabled students (Hamilton et al, 2020). In addition, after being studied by the researcher herself, students with special needs found it difficult to learn by distance learning besides their would-be teachers' feeling of worry about students' lack in educational progress due to the rarity of necessary educational tools. Hence, teachers have to make a good use of the pandemic and prepare themselves to teach students with special needs during covid-19 pandemic. So, it is necessary to reinforce skills of teachers to educate students with special needs in a default environment by depending on innovative ways of teaching such as using virtual platforms, collaboration with other teachers and keeping communication with students and their parents. Referring to what has been mentioned above; we can display the main question of the study: how effective is using interactive collaborative media to improve skills of mathematics teachers to educate students with special needs during covid-19? There are also a few secondary questions:

1. What are skills of mathematics teachers to educate students with special needs during covid-19 pandemic?

2. What is the suitable educational model to help mathematics teachers to educate students with special needs during covid-19 pandemic?

3. How effective is using interactive collaborative media to improve cognitive skills of mathematics teachers to educate students with special needs during covid-19 pandemic?

4. How effective is using interactive collaborative media to improve performance skills of mathematics teachers to educate students with special needs during covid-19 pandemic?

Aims of the study:

1. Preparing a suitable educational model to help mathematics teachers to educate students with special needs during covid-19 pandemic?

2. Defining skills of mathematics teachers to educate students with special needs during covid-19 pandemic?

3. Exploring effectiveness of using interactive collaborative media to improve cognitive skills of mathematics teachers to educate students with special needs during covid-19 pandemic?

4. Exploring effectiveness of using interactive collaborative media to improve performance skills of mathematics teachers to educate students with special needs during covid-19 pandemic?

\section{Significance of the study:}

Causing several harms for students with special needs, covid-19 forced those students to adapt to new ways of learning namely distance learning, which was difficult for them; the thing, which led special teachers to upgrade their teaching skills to cope with the latest Innovations during covid-19 pandemic. Results of the study showed the following:

1. There was no statistically significant difference at the level of 0,01 between scores means of experimental and controlling group students in the post application of the cognitive achievement test concerning skills of educating students with special needs during covid-19 pandemic as a whole unit.

2. There was no statistically significant difference at the level of 0,01 between scores means of experimental and controlling group students in the post application of the performance observation card concerning skills of educating students with special needs during covid-19 pandemic as a whole unit plus dealing with each separate skill : encouraging interaction and collaboration with colleagues and families, encouraging default interaction, designing mathematics lessons according to the comprehensive design for fairness and accessibility, educating mathematical concepts and skills, using technological teaching strategies and evaluating students.

\section{Definition of Terms:}

Interactive collaborative media: the researcher defines it as an important learning environment including Microsoft tools (Sway - Stream - Teams) besides educational content, interactive videos and PowerPoint presentations allowing communicating with others. 
Students with special needs: the researcher defines it as a group of students with mathematics learning difficulties.

Covid-19 Pandemic: it is a global epidemic spread at Wuhan in China late of 2019.

Skills of mathematics teachers to educate students with special needs during covid-19 pandemic by distance learning: the researcher defines it as a group of teaching behaviors displayed in activities done by special mathematics teachers when educating students with disabilities online during covid-19 as follows:

1. Encouraging communication and collaboration with colleagues and families.

2. Encouraging default interaction.

3. Designing mathematics lessons according to the comprehensive design for fairness and accessibility.

4. Educating mathematical concepts and skills.

5. Using proper technological strategies of teaching.

6. Evaluating students.

\section{Theoretical Frame}

Before covid-19, virtual ways of teaching were used such as WhatsApp and Facebook but they lack in depth and reliability. During covid-19, teachers depended on up-to-date ways namely Zoom, Teams, Moodle.

\section{Microsoft Teams}

It is defined as a digital center collecting conversations, content, homework and applications to provide a room for communication and exchanging ideas and experiences among teachers and students in default classes (Poston, Apostel and Richardson, 2020).

Covid-19 has a negative effect on the educational process. Consequently, teachers all over the world had to adopt new ways of teaching especially distance learning. Due to the need of social distance for protecting health, Microsoft Teams prepared default platforms to lessen feelings with isolation between teachers and students plus guaranteeing continuity of learning. Thus, virtual platforms, Microsoft Teams, play an important role in educating students (Al marzooq, 2020). Platforms, by no means, benefitted students greatly by providing opportunities of virtual meeting face to face as a synchronic teaching to school times every week. Students can do homework and study online by themselves. Microsoft Teams have a lot of advantages including holding virtual classes for sharing files and sheets successfully besides uploading PowerPoint presentations, videos and e-books in addition to making video calls and writing down notes related to different lessons (Barry \& Kanematsu, 2020)

Using interactive collaborative media to prepare special mathematics teachers

Covid-19 forced educators to create alternative ways of teaching; the thing, which led many teachers to depend on online teaching and using digital resources to make new curricula (Eickmann \& Gerick, 2020). One of the advantages of the pandemic that it tried to eliminate what is called digital illiteracy. Electronic platforms have helped greatly would-be mathematics teachers to improve their self-efficiency (El ahwal, 2020). No doubt that information and communication techniques (ICT) plus digitalism helped teachers to depend on online teaching during schools closure.

Importance of enabling students with special needs to consume learning during the pandemic

UNESCO has directed its attention to care with distance learning in order to satisfy the needs of students who are eager to learn. To add, virtual classes focus greatly on the student and consider him or her the main axis of the online educational process. In order to support students with special needs, strategies of active learning have to be included and shared with all students. Through these practices, teachers confirmed the importance of creating balanced classes for developing academic skills of students at official schools to meet desired expectations (Zamira et al, 2020, p. 14).

Technological complement is considered an essential factor for academic achievement of students with special needs. UNESCO (2020) stated shocking facts about students with special needs who receive insufficient educational support due to Covid-19 pandemic. So, it provided some strategies to help those students such as amending curricula, comprehensive design of learning (UDL), project - based learning, guaranteeing sharing the team of individual educational program of children (IEP) besides mutual collaboration between parents and teachers (UNESCO, Bangkok, 2020)

Since teachers showed inability of understanding the idea of comprehensive distance learning during covid-19 pandemic, it has become necessary to include technology study in curricula. Furthermore, in many cases, teachers lack in necessary resources to implement online teaching successfully (Colsd, 2016). Other studies (De la Varre et al,. 2014) showed that students with special needs were not clever at learning and doing their homework online due to little motivation, technological problems, time and space intervals and low parental support.

Practices and strategies of innovative teaching for reinforcing students with special needs during covid19 pandemic

The idea of designing a comprehensive teaching environment is represented in focusing on different intelligences and needs plus considering language skills of students. In addition, there should be extra aids inside classes to help disabled students besides providing classes with manual tools, educational activities, UDL programs and evaluation skills. These strategies enable students to be flexible in representing their ideas and participating effectively with other colleagues through an international learning models and different educational styles. Teachers, inside comprehensive classes, cannot deal easily with disabled students, so they should use various types and ways of curricula to assist students with special needs to express themselves (Chalasani, 2021)

In the same respect, Baker and David, 2012, demonstrated in their study other ways of encouraging 
students with special needs such as gaming and doing projects to evaluate them. Ford, 2013, suggested common teaching, differentiating learning and pair work between peers to support those who suffer from learning difficulties. Efficiency of teachers is considered an important aspect of applying comprehensive teaching inside classes which needs civil work and interaction with students with special needs.

Basics of effective online learning for students with special needs

During suspension of studying at schools, virtual and online learning have become a necessity for all students in general and for students with special needs in particular. There are effective practices which Reinforce both teachers and students (Visiosky, West ed and Hunziker, 2020) as follows :

1. Vocational development and supporting teachers

- Training teachers to use educational platforms successfully.

- Providing support for platforms.

- Providing virtual development for teachers who follow new styles.

\section{The family participation}

- Early participation of families at the process.

- Providing opportunities for parents to communicate with teachers.

- Encouraging parents to follow instructions which are put by teachers to help children.

\section{Accessibility}

- Choosing carefully tools of online teaching which support students with different abilities.

- Investigating the ability of teachers concerning sharing data with students.

- Depending on virtual platforms that can be operated mutually with current school systems.

- Helping teachers to use concepts of designing thought or comprehensive learning to reconcile between learners' needs and technology.

\section{Educational strategies for supporting specialization}

- Encouraging students to express their opinions toward instructional practices inside and outside classrooms.

- Asking help from students to design a fair educational online environment by encouraging them to express their opinions of the new educational innovations.

- Tending to sympathy when applying new learning methods.

The role of teachers in helping students with special needs during covid-19 pandemic online

Pandemics, by no means, affected negatively students with special needs, but they played also an effective role in Reinforcing participation and communication with others plus forming positive relationships. Yazcayir \&
Gurgur, 2020, confirmed the importance of existing suitable infrastructure and technological intelligence of teachers to implement online teaching successfully. The role of teachers in reinforcing communication with students with special needs can be summarized in prioritizing emotional and social aspects before academic learning, providing immediate feedback and support for students besides working with team spirit (Branst et al, 2020; Yazcayir \& Gurgur, 2020) introduced in their study how to educate students with special needs during covid19 in the light of comprehensive learning according to the following practices :

1. Watching lessons on TV.

2. Making online lessons and TV ones by teachers.

3. Uploading work paper on WhatsApp to be available for all classes.

4. Teachers have to contact parents to know whether students did homework or not or to make notes about students' work.

5. Providing services of special teachers after school time through any private institutions.

After reviewing the previous studies and literatures (Kaufman, 2020; UNCEF, 2021), the researcher defined skills for teaching students with special needs during covid-19 pandemic as follows:

1. Encouraging communication and collaboration with colleagues and families: teachers and their colleagues have to work together to solve learning problems or behavioral challenges to satisfy demands of students with special needs during covid-19 pandemic. Related researches refer to the good effect of positive participation between schools and families; the thing which force parents to support their children and be in contact with the latest instructional strategies (Kaufman, 2021).

2. Encouraging virtual interaction : it is important for students with special needs interact virtually with their teachers.

3. Designing mathematics lessons according to the comprehensive design for fairness and accessibility : that need Preparing lesson plans and work paper according to the academic aims.

4. Educating mathematical concepts and skills: some students face a problem of understanding some abstract mathematical concepts; so it is necessary to help students know these concepts to make mathematics easier.

5. Using flexible methods of technological teaching: it helps students to acquire necessary skills of distance learning especially during covid-19 pandemic.

6. Evaluating students: it is important to evaluate students to investigate the ability of students to adapt to distance learning. 
Challenges and opportunities of educating students with special needs during covid-19 pandemic

Covid-19, in fact, has directed our attention to issues of equality and challenging faced by students with special needs. Students who live in the countryside and find it difficult to access to technology feel injustice(Fishban \&Tomer, 2020). Teachers reported that $86 \%$ of students faced difficulties of accessing the internet whereas $64 \%$ of students do not have necessary required technological appliances and $38 \%$ of teachers can not access the internet (Hamilton et al, 2020). One of the most prominent problems faced by students during covid-19 pandemic is the inability of communicating with their teachers who are not able to communicate with parents either especially during quarantine. That gap of communication affected badly students who are in bad need for interaction with their peers and teachers (Yazcayir, Gurgur \& Schaeffer, 2020).

In order to achieve fairness and make balance between all students, it is a must to blend non digital alternatives represented in TV and digital ones represented in the internet (Reich et al, 2020). Furthermore, it is necessary for teachers to adapt to teaching in a default environment from home through activities. The academic content can be delivered via internet, radio or TV (Bender, 2020).

\section{Methodology}

\section{Procedures of the Study}

Participants of the Study are 60 male and female students enrolled in the third year of mathematics department, faculty of education, Tanta University in the second term of the year $2020 / 2021$. The experimental group includes 30 students and the controlling group includes 30 students who were chosen randomly. Seven sessions were provided online using the platform, for the experimental group, while the control group received the same content using the traditional method, face to face inside the classrooms.

\section{- The Study method and environmental design}

The recent Study depended on the quasi-experimental method and the pre and post application for experimental and controlling groups in which ways of collecting quantitative and qualitative data were used.

\section{The Study tools}

First: A test of cognitive achievement related to skills of teaching students with special needs

- Defining the Study aim: the Study aimed at measuring levels of memorization, understanding and application for students at faculty of education, department of mathematics, Tanta University in the second term of the year $2020 / 2021$.

- Defining kinds of the test phrases: there are 27 phrases related to 4 alternatives marked by 1 for each correct answer and 0 for each wrong one.

- Forming behavioral aims: these aims are related to topics of students with special needs, clever and creative students and learning difficulties in accordance to cognitive levels: memorization, understanding and application. The Studyer amended these behavioral aims after being judged by specialists and experts.

- Defining significance and proportional weights of the test: the following table shows the significance and the proportional weight of each topic and skill for students with special needs during covid-19 pandemic.

has a really negative impact on the educational process; the thing which led to the complete closure of schools and universities to achieve physical distance which plays a role in limiting the spread of covid-19. Consequently. that emergency forced the educational institutions to make obligatory transformation in their teaching systems (Yulia. 2020) to guarantee the continuity of learning. That kind of transformation from the traditional teaching to digital one is considered a very systematic issue that needs providing the necessary tools and equipment to do so (Al Salmy. 2020). Thus. transforming from the traditional technique to a virtual one created some obstacles for both students and members of teaching staff at College of Continuing Education and Community Service at Imam Muhammad bin Saud Islamic University. So. the study aims to answer the following questions:

1. What are obstacles facing members of teaching staff at College of Continuing Education and Community Service at Imam Muhammad bin Saud Islamic University during covid-19?

2. What are the obstacles facing the students at faculty of Continuing Education and Community Service at Imam Muhammad bin Saud Islamic University during covid-19?

3. What are the required educational transformations to be existed at faculty of Continuing Education and Community Service at Imam Muhammad bin Saud Islamic University during covid-19?

Table (1) significance and proportional weight

\begin{tabular}{|l|c|c|c|c|c|}
\hline Topics & \multirow{2}{*}{$\begin{array}{l}\text { Relative } \\
\text { weight }\end{array}$} & remembering & understanding & application & $\begin{array}{c}\text { Number } \\
\text { of } \\
\text { vocabular } \\
\mathbf{y}\end{array}$ \\
\cline { 3 - 6 } & $33 \%$ & $41 \%$ & $26 \%$ & 9 \\
\hline $\begin{array}{l}\text { Introduction to } \\
\text { people with } \\
\text { special needs }\end{array}$ & $32 \%$ & 3 & 4 & 2 & 9 \\
\hline $\begin{array}{l}\text { Outstanding } \\
\text { and creative }\end{array}$ & $33 \%$ & 3 & 4 & 2 & 9 \\
\hline $\begin{array}{l}\text { Learning } \\
\text { difficulties }\end{array}$ & $35 \%$ & 3 & 4 & 6 & 27 \\
\hline Total & $100 \%$ & 9 & 12 & & \\
\hline
\end{tabular}

The initial experiment of the test:

- The test validity: the test was judged by a group of consultants and experts of mathematics teaching methodology professors to identify the suitability of the test phrases to measure the cognitive aspect related to skills of teaching mathematics for students with special needs plus testing the linguistic accuracy of phrases. Thereafter, the Studyer applied the experts' notes on the test which became ready to be applied. 
- Reliability of the test: the Studyer performed an initial experiment on ten of third year students at faculty of education, Tanta University, department of mathematics in the second term of the year 2020 /2021. After application, inner validity measured by correlation coefficients of each phrase was calculated plus the total score of the test which ranged between 0,765 and 0,882 ; the value which is significant at the level of 0.01 . So, phrases of the test are consistent.

- Reliability of cognitive achievement test related to skills of teaching students with special needs: the coefficient of the test validity was measured by Cronbach's Alpha which was 0,783 which was significant at 0.01 .

- Defining the test time: the time taken to finish the test was 40 minutes divided into 35 minutes as time means that was enough for answering questions plus 5 minutes for giving instructions.

- The final version of the test: after measuring the statistical coefficients, the test became ready to be applied. It included 27 phrases and the total degrees was 27.

Second: a card of performance observation of the would-be teachers concerning skills of online teaching for students with special needs.

1. Defining the aim of the card: it aimed at measuring performance of the would-be teachers for skills of online teaching for students with special needs.

2. Dimensions of the observation card

- Encouraging communication and collaboration with colleagues and families.

- Designing mathematics lessons according to the comprehensive design for fairness and accessibility.

- Educating mathematical concepts and skills.

- Using flexible methods of technological teaching strategies.

- Evaluating students.

3. Designing the observation card

- Part one: it includes instructions and general data including name of the teacher and student, year, major, curriculum, description of the card, level of performance and grades.

- Part two: it includes phrases describing performance of the would-be teachers for each skill of educating students with special needs. Three items annex each phrase: performed with a great degree, performed by a medium degree and performed by a weak degree. The teacher is required to notice performance of students according to each phrase by ticking (yes) to what agree with their performance. The card includes 5 main skills with 67 indicators as follows:
Table (2) main and secondary skills of the observation card

\begin{tabular}{|l|c|c|}
\hline \multicolumn{1}{|c|}{ The main skill } & $\begin{array}{c}\text { Number } \\
\text { of } \\
\text { indicators }\end{array}$ & Percentage \\
\hline $\begin{array}{l}\text { Encourage sharing and } \\
\text { communicating with colleagues } \\
\text { and families. }\end{array}$ & 20 & $30 \%$ \\
\hline $\begin{array}{l}\text { Design math lessons according to } \\
\text { the overall design of learning for } \\
\text { equity and accessibility. }\end{array}$ & 9 & $13 \%$ \\
\hline $\begin{array}{l}\text { Teaching mathematical concepts } \\
\text { and skills. }\end{array}$ & 11 & $16 \%$ \\
\hline $\begin{array}{l}\text { Use flexible technological } \\
\text { teaching strategies. }\end{array}$ & 17 & $25 \%$ \\
\hline Student learning assessment & 10 & $15 \%$ \\
\hline Total & 67 & $100 \%$ \\
\hline
\end{tabular}

4. Grading the card: the total grade of the card was made by marking the great performance by 2 marks, medium performance by 1 mark and zero for the weak performance.

5. Defining validity of the card: it was judged by a group of consultants and experts in curricula and teaching methodology; the Studyer complied to their initial notes.

6. Reliability of the card: coefficient of the card reliability was measured by Cronbach's Alpha which was 0,879 . This assured the high rate of the card reliability.

7. Designing the final shape of the observation card: after measuring the statistical coefficients, the card has become ready to be applied as it includes 67 indicators and the maximum value was 134.

An educational model for helping special mathematics teachers to educate students with special needs during covid-19 pandemic online

Covid-19 forced schools and universities to transform from traditional learning to default one. At the same time, the Studyer used a pedagogical model (CAFE) to help teachers educate students with special needs during covid19 pandemic online (Wang, 2020). The model consists of four stages:

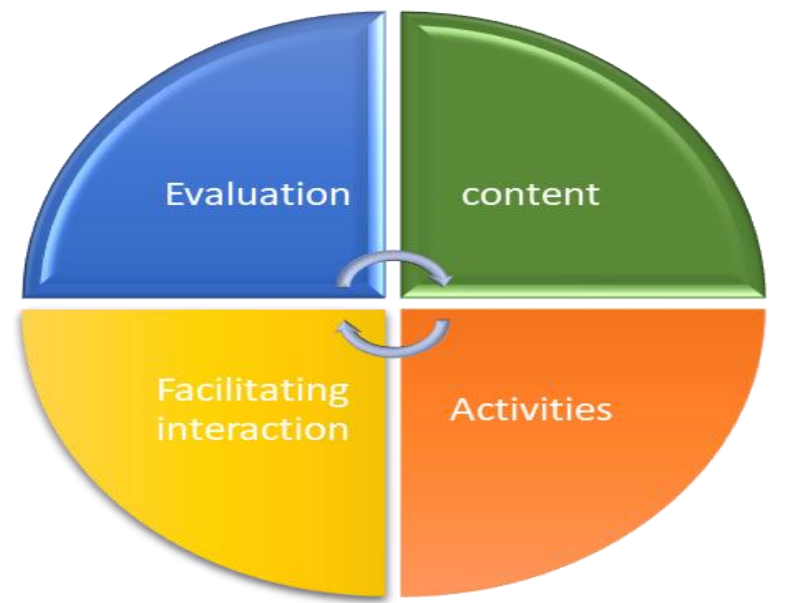

Fig (1): a pedagogical model for online teaching during covid-19 pandemic 
First: content there are four levels of the content as follows:

- The level of content: it is about second term curriculum of teaching methodology of students with special needs.

- Level of the unit: the pedagogical content was regulated by labeling each unit and writing its educational aims.

First unit: an introduction of students with special needs. A would-be teacher has to be able to do the following at the end of this topic:

1. Being aware of the special education.

2. Classifying special groups.

3. Illustrating ways of educating the blind and the deaf.

4. Comparing between physically and mentally disabled.

5. Comparing between audio and visual disability and how effective it is to pedagogical process.

6. Focusing on the general basics of educating students with special needs.

7. Explaining students with special needs' requirements of instructional technology.

8. Defining ways of supporting deaf and blind students through online learning during covid-19 pandemic.

9. Defining ways of supporting students who suffer from visual disability effectively via distance learning during covid-19 pandemic.

Second unit: creative and clever students

At the end of this topic, the would-be teachers have to be able to do the following:

1. Distinguishing between cleverness and talent.

2. Explaining the main types of scientific advance.

3. Stating mental properties of clever students.

4. Explaining steps of figuring clever students.

5. Defining personal properties of the teacher of clever and talented students.

6. Writing a list of teachers' behaviors and how they affect a class atmosphere.

7. Deducing pedagogical ways that are suitable for clever students.

8. Defining problems faced by students.

Third unit: learning difficulties

At the end of this topic, the would-be teachers have to be able to do the following:

1. Defining learning difficulties properly.

2. Explaining relationships between learning difficulties, school retardation and mental backwardness.

3. Stating shapes of learning difficulties.

4. Stating ways of measuring and diagnosing learning difficulties.

5. Inducing tools of measuring and diagnosing learning difficulties.

6. Explaining the importance of early diagnosis of learning difficulties.

7. Deducing ways and programs of treatment.
8. Defining strategies of educating students with learning difficulties.

9. Explaining the service to be introduced by schools to students with learning difficulties.

10. Defining ways of educational support which should be suitable for students with learning difficulties inside default classes during covid-19 pandemic.

Fourth unit: skills of educating students with special needs during covid-19 pandemic.

At the end of this topic, the would-be teachers have to be able to do the following

1. Encouraging communication and collaboration with colleagues and families.

2. Encouraging default interaction.

3. Designing mathematics lessons and evaluating students.

4. Using flexible methods of technological teaching strategies.

5. Educating mathematical concepts and skills.

The level of lessons: there are three steps of designing lessons according to the comprehensive design: first step, which aims to analyzing the target of the lesson through participation, representation and expressing actions, second step which focuses on controlling the lesson besides the third step which focuses on thinking and redesigning lessons.

The level of activity: a teacher has to provide lessons with reading patterns, activities, instructions, homework, projects and other technological tools.

\section{Second: activities}

They are efforts to help students achieve learning outcomes. These activities may be collaborative projects, tests, contests, or discussions. The Studyer did the following:

1. Making sure that online activities go along with similar experiences of traditional classes.

2. Asking the would-be teachers to make sure that instructions if activities are written clearly.

3. Making a pedagogical model including a new system.

4. Making sure of activities test at the platform.

Pedagogical activities across the educational platform included the following:

1. Designing a parent guide including how to use technology and communicative strategies at home.

2. Doing a cooperative project with colleagues showing ways of supporting students who suffer from visual disability effectively via distance learning during covid-19 pandemic.

3. Writing down a report about how to help students with learning difficulties inside default classes during covid-19 pandemic.

4. Making discussions online or uploading a summary of a class work.

5. Recording a video conversation to review a chapter of a book.

6. Making a plan for educating students with special online during covid- 19 . 
7. Making mathematical lesson plans by using PowerPoint programs dealing with real problems according to the comprehensive design of education.

8. Designing online activities focusing on students' life.

9. Participating in forums and discussions online to achieve understanding and building relations.

10. Designing a presentation including ways and tools of digital evaluation of students with special needs.

11. Preparing a summary for ways of evaluating students with special needs.

Third: facilitating interaction

For facilitating interaction depended on three kinds of interaction when teaching during the pandemic:

- Interaction between learners and the content: introduced the content and presentations on platforms using Microsoft tools and asked students to coordinate the subjects.

- Interaction between learners and teachers: in order to communicate regularly with the class, depended on Microsoft tools to send videos and voice messages. Furthermore, virtual work hours and supporting students was defined by plus giving feedback, encouraging, and controlling students in suitable time. Moreover, video conferences and individual communications were held to satisfy the social and cognitive aspects for students.

- Interaction between learners themselves: learners were encouraged to cooperate and exchange ideas via Microsoft Teams; one of the students was chosen to be a leader of the group and giving support to colleagues. Also, and referred to the interaction between content and learners as a preparation for interaction between learners themselves to guarantee reading before sharing ideas with others. and gave advice to some students when it was necessary.

\section{Fourth: evaluation}

For evaluation used different sources of data to evaluate the would-be teachers online during the pandemic through the following steps:

1. used the accumulative test and performance data taken by Microsoft to evaluate students comprehensively besides defining times in which students do projects, discussions and helping their colleagues.

2. used peer evaluation for cooperative projects.

3. depended on self-evaluations done by the wouldbe teachers themselves to encourage them to reflect learning skills online.

\section{Results \& Discussing}

Discussing results of the first question (what are the skills of mathematics teachers to educate students with special needs during covid-19 pandemic online?)

After referring to the previous studies in this field, the Studyer asked some consultants and experts of mathematics teaching methodology to give options of mathematics teachers' skills collected by the Studyer with the goal of amendment or omitting the unnecessary ones. The final list of skills, after taking experts' opinions included: skills of distance teaching, encouraging collaboration with colleagues and families, designing mathematics lessons according to the comprehensive design for fairness and accessibility, educating mathematical concepts and skills, using flexible technological teaching strategies and evaluating students.

Discussing results of the second question

The second question (what is the suitable educational model to help mathematics teachers to educate students with special needs during covid-19 pandemic online?) was discussed in detail in the point of procedures of the Study. To conclude, the Studyer used CAFE which is an educational model to help mathematics teachers to educate students with special needs during covid-19 pandemic online.

Discussing results of the third question (how effective is using interactive collaborative media to improve cognitive skills of mathematics teachers to educate students with special needs during covid-19 pandemic?)

To answer that question, there was the first hypnosis which stated that there was no statistically significant difference at the level of 0.01 between participants' mean scores of the experimental and controlling groups in the post - cognitive achievement test concerning skills of educating students with special needs during covid-19 pandemic online as a whole unit.

- Testing the validity of the first hypnosis:

Means, standard deviations for participants in the experimental and controlling groups in the post cognitive achievement test concerning skills of educating students with special needs during covid19 pandemic online as a whole unit and at its three levels: understanding, memorizing and application. The following table shows results

Table (3) The Participants' mean scores, standard deviation, tvalue, and level of significance in the post-achievement

\begin{tabular}{|l|l|l|l|l|l|l|l|}
\hline \multicolumn{1}{|c|}{ variable } & groups & $\mathbf{N}$ & Mean & $\begin{array}{c}\text { Std. } \\
\text { Deviation }\end{array}$ & t & df & $\begin{array}{c}\text { Sig. } \\
\text { (2- } \\
\text { tailed) }\end{array}$ \\
\hline $\begin{array}{l}\text { cognitive } \\
\text { achievement }\end{array}$ & control & 30 & 13.5 & 1.04221 & 53.31 & 58 & 0.01 \\
\cline { 2 - 8 } & experimental & 30 & 25.16 & 0.59209 & & & \\
\hline
\end{tabular}

The findings in Table (3) have indicated that the mean scores of the Study participants of the experimental group are higher than the mean scores of the participants of the control group in the post-cognitive achievement. Further, the t-value is (53.31) which is significant at the (0.01) level. Hence, the first hypothesis of the Study was confirmed. Besides, the mean scores of the Study participants of the experimental and control groups in the 
post-administration of the cognitive achievement in the following figure:

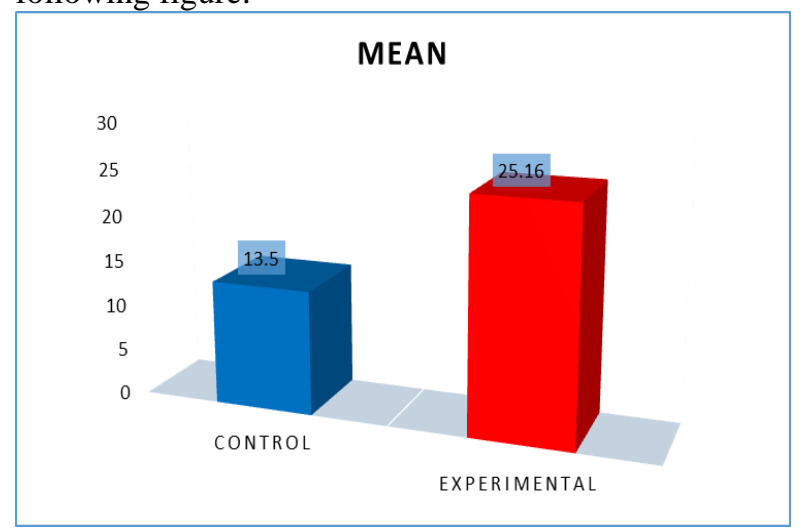

Fig (2): A statistical representation of the Study participants' mean scores in the post- cognitive achievement

\section{Testing validity of the second hypnosis:}

To answer this question, there was the second hypnosis which stated that there was no statistically significant difference at the level of 0.01 between participants' mean scores of the experimental and controlling groups in the post - performance observation card concerning skills of educating students with special needs during covid-19 pandemic online as a whole unit and at each skill of the following : encouraging interaction and collaboration with colleagues and families, encouraging default interaction, designing mathematics lessons according to the comprehensive design for fairness and accessibility, educating mathematical concepts and skills, using flexible technological teaching strategies and evaluating students. Means, standard deviations for participants' scores of the experimental and controlling groups in the post - performance observation card concerning skills of educating students with special needs during covid-19 pandemic online as a whole unit and at each skill of the following : encouraging interaction and collaboration with colleagues and families, encouraging default interaction, designing mathematics lessons according to the comprehensive design for fairness and accessibility, educating mathematical concepts and skills, using flexible technological teaching strategies and evaluating students. The following table shows results:

Table (4) The Participants' mean scores, standard deviation, $t$ value, and level of significance in the post- Observation

\begin{tabular}{|c|l|l|l|l|l|l|l|}
\hline variable & groups & $\mathbf{N}$ & Mean & $\begin{array}{c}\text { Std. } \\
\text { Deviation }\end{array}$ & $\mathbf{t}$ & df & $\begin{array}{c}\text { Sig. } \\
(\mathbf{2}- \\
\text { tailed) }\end{array}$ \\
\hline \multirow{2}{*}{ Observation } & control & 30 & 48.9667 & 2.10882 & & & \\
\cline { 2 - 8 } & experimental & 30 & 128.6333 & 3.47884 & & 587.262 & 58.01 \\
\hline
\end{tabular}

The findings in Table (4) have indicated that the mean scores of the Study participants of the experimental group are higher than the mean scores of the participants of the control group in the post- skill performance Observation. Further, the t-value is (107.262) which is significant at the (0.01) level. Hence, the first hypothesis of the Study was confirmed. Besides, the mean scores of the Study participants of the experimental and control groups in the post-administration of the Observation skill performance in the following figure:

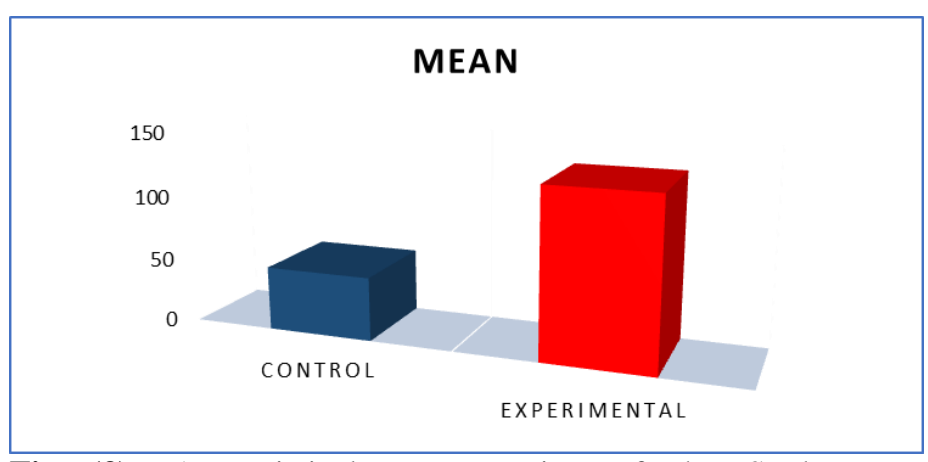

Fig (3): A statistical representation of the Study participants' mean scores in the post- Observation skill performance

\section{Conclusion}

Using interactive collaborative media demonstrated a significant improvement in the performance of the experimental group participants concerning skills of mathematics teachers to educate students with special needs. The would-be teachers have to be more creative and make an interactive atmosphere of communication with students; the thing which requires acquiring the following skills : encouraging interaction and collaboration with colleagues and families, encouraging default interaction, designing mathematics lessons according to the comprehensive design for fairness and accessibility, educating mathematical concepts and skills, using flexible technological teaching strategies and evaluating students. Hence, once acquiring these skills of communication and collaboration, the would-be teachers will be able to educate students with special needs.

\section{Recommendations \& suggestions}

1. It is necessary to care with special mathematics teachers at faculties of education to support students with special needs online during crises.

2. Focusing on the role of families to develop their academic roles.

3. Preparing overall plans and programs to help education leaders introducing services for special education during pandemics.

4. Making a cooperative program between teachers and families to make learning available during pandemics.

5. Listening to teachers' opinions about distance learning during pandemics. 
6. Investigating effectiveness of evidence - based practices to consume teaching mathematics online for students with special needs during covid-19 pandemic.

7. Knowing the effect of teachers' mentalities on educating students with special needs online.

\section{References}

[1]. Almarzooq, Z. I. (2020). Virtual Learning During the COVID-19 Pandemic, JOURNAL OF THE AMERICAN COLLEGE OF CARDIOLOGY, VOL. 75, NO. 20

[2]. Baker, D. \& David S. (2012, November). Learning disability quarterly. $A n$ Accommodations Model for the Secondary Inclusive Classroom, 35(4), p. 212-224. https://www.jstor.org/stable/41702375

[3]. BARRY, D. and KANEMATSU, H.( 2020). TEACHING DURING THE COVID-19 PANDEMIC,

[4]. Bender, L. (2020). Interim Guidance for COVID19 Prevention and Control in Schools. UNICEF.

[5]. Branstetter, R.(2020). How Teachers Can Help Students With Special Needs Navigate Distance Learning,

https://greatergood.berkeley.edu/article/item/how teachers_can_help_students_with_special_need s_navigate distance learning

[6]. Carol Ann Tomlinson \& McTighe Jay. (2006). Integrating differentiated instruction and understanding by design: Connecting Content and Kids. ascd.org publications.

[7]. Center on Online Learning and Students with Disabilities (COLSD) (2016). Equity Matters 2016: Digital \& Online Learning for Students with Disabilities

[8]. Chalasani, P. (2021). SUPPORTING STUDENTS WITH LEARNING DIFFICULTIES DURING COVID-19 ONLINE LEARNING, Master Thesis, University of the People.

[9]. Collaborative for Academic, Social, and Emotional Learning. (2020).

[10]. De la Varre, C., Irvin, M. J., Jordan, A. W., Hannum, W. H., \& Farmer, T. W. (2014). Reasons for student dropout in an online course in a rural $\mathrm{K}-12$ setting. Distance Education, 35(3), 324-344.

[11]. Durak, G. and Çankaya, S.( 2020). UNDERGRADUATE STUDENTS' VIEWS ABOUT EMERGENCY DISTANCE EDUCATION DURING THE COVID-19 PANDEMIC, European Journal of Open Education and E-learning Studies - Volume 5 Issue 1, P. 122- 147.

[12]. Eickelmann, B., and J. Gerick. 2020. "Lernen Mit Digitalen Medien: Zielsetzungen in Zeiten Von Corona Und Unter Besonderer Berucksichtigung Von Sozialen Ungleichheiten
[Learning with Digital Media: Objectives in Times of Corona and under Special Consideration of Social Inequities]." Die Deutsche Schule 16: 153-162. doi:10.31244/9783830992318.09.

[13]. El-ahwal, M.(2020). Effect of Micro-Teaching Method Supported by E-Learning Platforms inEnriching Pre-service Mathematics Teachers' Teaching Practice s And Improve Self-efficacy, International Journal of Instructional Technology and Educational Studies (IJITES), Volume1 / Issue3, PP.18-31.

[14]. Fishbane L. \& Tomer A. (March, 20, 2020). As classes move online during COVID-19, what are disconnected students to do? https://www.brookings.edu/blog/theavenue/2020/03/20/as-classesmove-

[15]. Ford, J. (2013). Educating students with learning disabilities in inclusive. Electronic Journal for Inclusive Education, 1-16.

[16]. Hamilton, L. S., Kaufman, J. H., \& Diliberti, M. (2020). Teaching and Leading through a Pandemic: Key Findings from the American Educator Panels Spring 2020 COVID-19 Surveys. Data Note: Insights from the American Educator Panels. Study Report. RR-A168-2. RAND Corporation.

[17]. Kaufman, T.(2021) National Center for Learning Disabilities Distance Learning Toolkit: Key Practices to Support Students Who Learn Differently. Lindsay DeHartchuck, Charles Doolittle

[18]. König,j., Jäger-Biela, $\quad$ D.j. \& Glutsch,N. (2020) Adapting to online teaching during COVID-19 school closure: teacher education and teacher competence effects among early career teachers in Germany, European Journal of Teacher Education, 43:4, 608622, DOI: $10.1080 / 02619768.2020 .1809650$

[19]. Laplante, P. (2020). Contactless U: Higher education in the postcoronavirus world. IEEE Annals of the History of Computing, 53(07), 7679.

[20]. Petretto, D. R., Masala, I., \& Masala, C. (2020). Special educational needs, distance learning, inclusion and COVID-19. Education Sciences, $10(6)$,

154. https://doi.org/10.3390/educsci10060154

[21]. Poston, J., Apostel, S., \& Richardson, K. (2020). Using Microsoft Teams to Enhance Engagement and Learning with Any Class: It's Fun and Easy.

[22]. Reich, J., Buttimer, C. J., Fang, A., Hillaire, G., Hirsch, K., Larke, L. R., ... \& Slama, R. (2020). Remote learning guidance from state education agencies during the covid-19 pandemic: A first look.

[23]. Sahu, P. (2020). Closure of universities due to coronavirus disease 2019 (COVID-19): Impact 
on education and mental health of students and academic staff. Cureus, 12(4), 1-6. e7541. DOI 10.7759/cureus.7541

[24]. Schaeffer K. (April 23, 2020). As schools shift to online learning amid pandemic, here's what we know about disabled students in the U.S. https://www.pewStudy.org/fact-

tank/2020/04/23/as-schools-shiftto- onlinelearning-amid-pandemic-heres-what-we-knowaboutdisabled-

[25]. Smith, C. (2020). Challenges and opportunities for teaching students with disabilities during the COVID-19 pandemic. International Journal of Multidisciplinary Perspectives in Higher Education, 5(1), 167-173.online-during-covid19-what-are-disconnected-students-todo/

[26]. Smith, S. J., Basham, J. D., Rice, M., Carter, R. A., Jr. (2016). Preparing special education teachers for online learning: Findings from a survey of teacher educators. Journal of Special Education

[27]. Stanford, B., \& Reeves, S. (2009). Making it happen: Using differentiated instruction, retrofit framework, and universal design for learning. Teaching Exceptional Children Plus, 5(6), n6.

[28]. Turky, M., Shahin, A., \& Soliman, N. (2020). Learning at Tanta University During the Covid19 Pandemic. International Journal of Instructional Technology and Educational Studies, 1(3), 18-21. doi: 10.21608/ihites.2020.42170.1032.

[29]. UNESCO Bangkok (2020). Empowering students with disabilities during the COVID19 crisis:

https://bangkok.unesco.org/content/empoweringstudents-disabilities-duringCovid-19-crisis

[30]. UNICEF (2021). PRACTICAL GUIDE TO BLENDED/REMOTE LEARNING AND CHILDREN WITH DISABILITIES.

[31]. Vislosky, E. WestEd and Hunziker, J.(2020). Going the Distance: Online Strategies for Helping Students with Disabilities https://ies.ed.gov/ncee/edlabs/regions/midatlantic /app/Blog/Post/1 34

[32]. Wang, C. X. (2020). CAFE: An Instructional Design Model to Assist K-12 Teachers to Teach Remotely during and beyond the Covid-19 Pandemic, Association for Educational Communications \& Technology, P. 8- 16.

[33]. Yazcayir, G., \& Gurgur, H. (2020). Students with Special Needs in Digital Classrooms during the COVID-19 Pandemic in Turkey. Pedagogical Study, 6(1), em0088. https://doi.org/10.29333/pr/9356

[34]. Zamira D \& Mirjeta N. (2020, June 18). The impact of the COVID-19 pandemic on the education of children with disabilities. Journal of Special Education. doi:10.13140/RG.2.2.17807.41125 